\title{
A!
}

This is an electronic reprint of the original article.

This reprint may differ from the original in pagination and typographic detail.

Kuronen, Henri; Mikkola, Esko; Hostikka, Simo

\section{Tensile strength of wood in high temperatures before charring}

Published in:

Fire and Materials

DOI:

$10.1002 /$ fam.2813

Published: 01/11/2021

Document Version

Peer reviewed version

Please cite the original version:

Kuronen, H., Mikkola, E., \& Hostikka, S. (2021). Tensile strength of wood in high temperatures before charring. Fire and Materials, 45(7), 858-865. https://doi.org/10.1002/fam.2813

This material is protected by copyright and other intellectual property rights, and duplication or sale of all or part of any of the repository collections is not permitted, except that material may be duplicated by you for your research use or educational purposes in electronic or print form. You must obtain permission for any other use. Electronic or print copies may not be offered, whether for sale or otherwise to anyone who is not an authorised user. 


\title{
TENSILE STRENGTH OF WOOD IN HIGH TEMPERATURES BEFORE CHARRING
}

\author{
Henri Kuronen \& Esko Mikkola \\ KK-Palokonsultti Oy, Finland \\ Simo Hostikka \\ Aalto University, Finland
}

\begin{abstract}
The main focus of this paper is on the tensile strength of wood in high temperatures. In the analysis of the previous studies, it was observed that results by different researchers varied quite a bit, eventhough a vast reduction of the tensile strength at elevated temperatures was clear in all of them. Thus, a need for further investigation into the matter became apparent. As a key part of this paper, steady-state tensile strength experiments below charring temperatures are carried out, and their results are analysed. The results are then used in analysing the tensile strength of a wooden beam subjected to a fire in an FDS fire simulation.
\end{abstract}

\section{INTRODUCTION}

\section{Motivation}

When designing timber structures, it is important to understand the phenomena occuring in the load bearing parts due to the fact that wood is a burning material which chars when it is exposed to high temperatures. When the charring happens, wood loses its structural strength. There are many different methods to assess when wood is completely charred, varying from temperature to certain limits in change of density. However, it should be kept in mind that wood starts to lose its strength at temperatures much lower than at which the actual charring happens. This can easily be seen in e.g. the reduction of its density before reaching the temperature of about $300{ }^{\circ} \mathrm{C}$, which is considered to be the pyrolysis temperature, at which charring is assumed to happen. This weakening of timbers structural strength properties before charring has been taken into account in some extent by Eurocode 5, utilizing an additional reduction of load-bearing dimensions ${ }^{1}$. However, this is based on a limited amount of data, but is assumed to be on the safe side. By examining the true load-bearing capability of wood under elevated temperatures, more precise information is to be gained, that will benefit not only the designers, but also the financiers of the building project.

\section{Wood as a construction material}

The use of wood as a construction material has become more and more common over the past decades, and will most likely continue this trend in the future. One of the reasons for this is its environmental friendliness. The use of concrete, for example, is much more wearing on environment than using wood and timber products. The effects of choosing building materials become evident because of the fact that the building sector uses 40 percent of total global annual energy consumption and produces 30 percent of total greenhouse gasses ${ }^{2}$. Improvement is needed in our modern, environmentally conscious society. Use of timber could be part of the solution, but in order of that to happen, it is important to understand its properties properly. 


\section{Properties of wood}

The main focus of this work is on tensile strength, which is one of the most important defining characteristics of the material, and is often used to define the strength class of the wood. Wood is an anisotropic material, meaning that its properties differ depending on which direction (longitudinal, radial, or tangential) it is reviewed. Longitudinal direction (parallel to grain) is chosen as the subject of the review, as it is the direction wood has the highest tensional strength in, and thus is the most common direction tensional stress is applied to it. Although wood behaves and is regarded as a viscoelastic material that begins to creep especially during cycles of changing moisture content and temperature, these properties take long to become observable ${ }^{3}$. Even for a detection of the phenomenon on a small scale, the time range is usually in days. Thus, the experiments that are performed within this work, are not affected by these properties, as the time range is in minutes.

\section{PREVIOUS STUDIES}

Most of the studies conducted on the fire behaviour of timber focus on charring. Still, there are a few studies concerning behaviour of wood at elevated temperatures, which do not involve charring. One of the most famous of these is the research conducted by König ${ }^{4}$. His study on the effect of temperature on elastic modulus and strength properties of wood have been recognized by CEN (Comit'e Europ'een de Normalisation, or European Committee for Standardization in english) and taken into account in the Eurocode 5. In 1985 B.A. Östman conducted a study ${ }^{5}$ on the tensile strength of wood at temperatures and moisture contents simulating fire conditions. She carried out her experiments with spruce (Picea excelsa) in temperatures up to $250{ }^{\circ} \mathrm{C}$, with a moisture content varying between 0 and $30 \%$ (moisture content in temperatures above $100{ }^{\circ} \mathrm{C}$ was $0 \%$, because of the vaporization of water. Based on the results, she deduced that both temperature and moisture content have a significant effect on the tensile strength of wood, and thus should both be taken into account. With a moisture content of $30 \%$, when the temperature of the spruce samples rose from $25{ }^{\circ} \mathrm{C}$ to 90 ${ }^{\circ} \mathrm{C}$, the tensile strength of wood may only be about $50 \%$ of its original value. When dry samples were examined, it was observed that at $200{ }^{\circ} \mathrm{C}$ the tensile strength had decreased to $60 \%$ and at $250{ }^{\circ} \mathrm{C}$ to $40 \%$ of its original value at $25{ }^{\circ} \mathrm{C}^{5}$. Figures 1 and 2 demonstrate the differences in the experimental data gathered by different researchers.

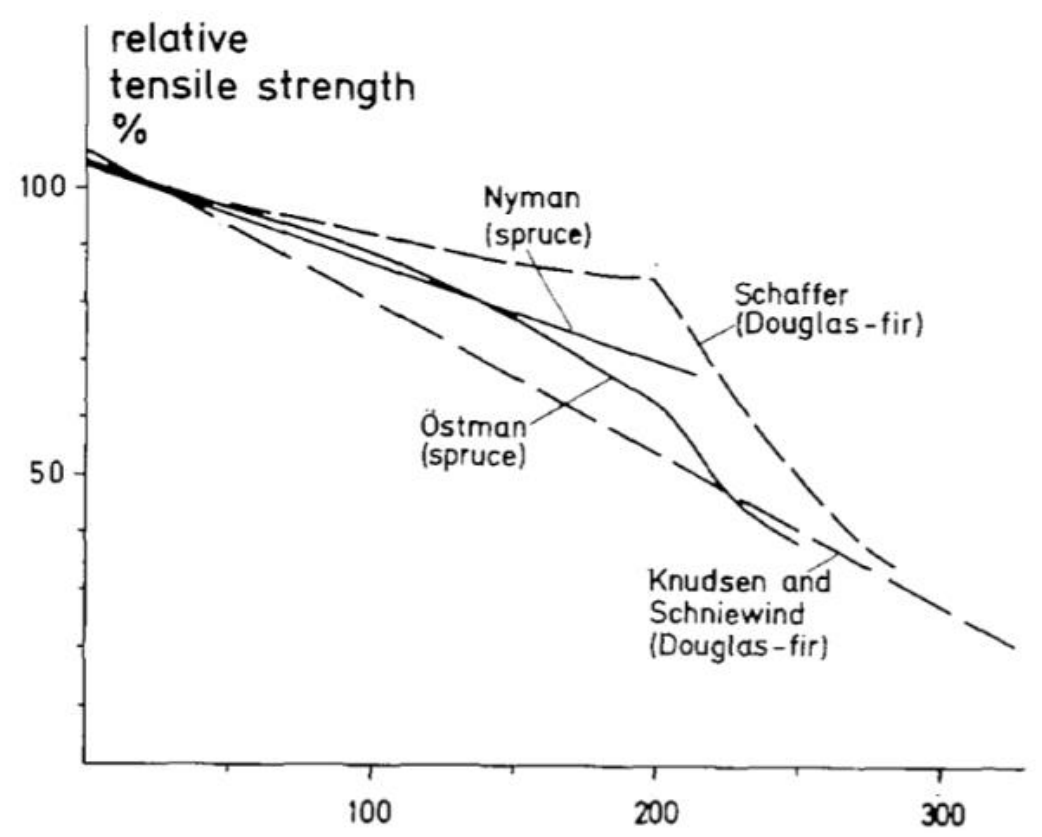

Figure 1. Graphical representation of results by Östman, in comparison with other studies. ${ }^{5}$ 


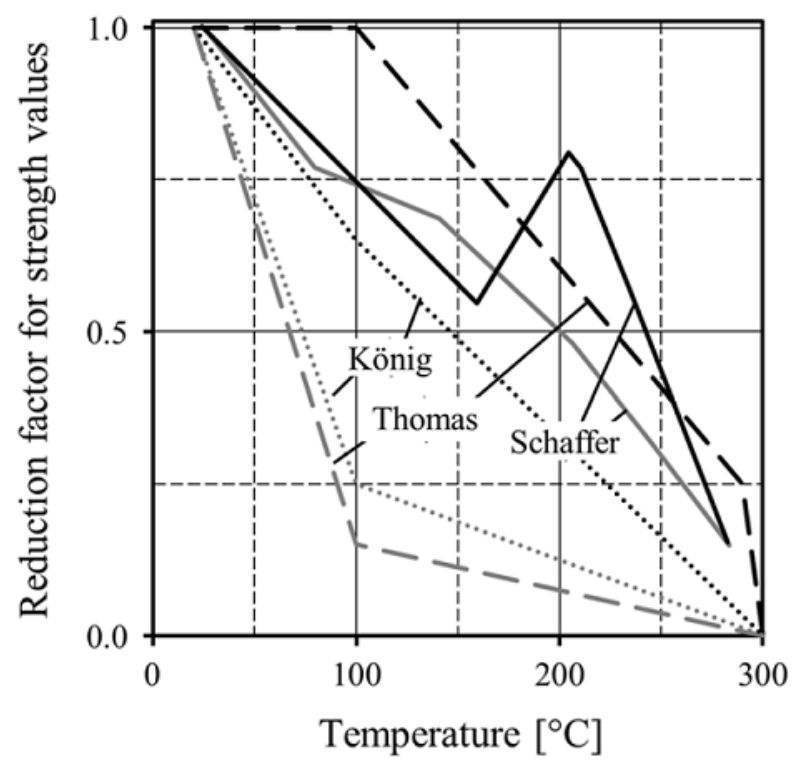

Figure 2. Graphical representation of the variation of compressional (grey lines) and tensional (black lines) strength as a function of temperature. ${ }^{6}$

Östmans results show greater tensile strength than those of Königs, which are included in the Eurocodes. The results by König should be valid for softwoods, which spruce belongs to (although, species of wood are not itemized in the Eurocode). Thus, the Eurocode seems to be overlyconservative. This is good for safety, but bad from an economical point of view.

However, this wide applicability and openness for interpretation raises the possibility for both overand under dimensioning, which can lead to reductions in safety or monetary gains. Data by different researchers differ from each other quite a bit, and taking into consideration that Eurocode 1995-1-2 has temperature dependent reduction factors in strength properties produced by König, clearly consideration and further inspection and experiments into these properties is needed. This will be tackled in the next chapter.

\section{TENSILE TESTS}

\section{Experimental principles}

For the purpose of this paper and confirming the relationship between tensile strength and temperature, tensile tests were carried out at different temperatures. The experiments were conducted with 56 spruce samples at a constant temperature as a steady-state test, increasing the tensile stress until breakage. In order to get data on the effect of temperature, the experiment was conducted at different temperatures, with an interval of $25{ }^{\circ} \mathrm{C}$. Even though $300{ }^{\circ} \mathrm{C}$ is considered to be the pyrolysis temperature at which the wood chars, decomposition of wood can happen well before reaching this temperature. This is why the experiments were only conducted up to $250{ }^{\circ} \mathrm{C}$. In order to increase the reliability of the results, three individual tests were carried out at each temperature, for both ovendry and moist samples. When the sample has reached the temperature of $125{ }^{\circ} \mathrm{C}$, all moisture can be assumed to have evaporated, and these samples are considered to be ovendry. Still, also moist samples were tested at each temperature, in order to prove this assumption, and also to increase the number of samples, thus reducing the significance of randomness. The moist samples had been stored in a room with RH 45 and temperature of $20{ }^{\circ} \mathrm{C}$. This was done to represent real life conditions, at which the timber structures often are. The moisture content of the samples, defined by oven drying and weighing, was approximately $10 \%$ (the average was $10,3 \%$, with a standard deviation of $0,2 \%$ ). This corresponds relatively well to the relationship between temperature, relative humidity and moisture content. The test matrix below visualizes the conditions of the tensile tests conducted. 
Table 1. Numbers of samples tested in given conditions

\begin{tabular}{|c|c|c|}
\hline $\begin{array}{c}\text { Temperature } \\
{ }^{\circ} \mathrm{C}\end{array}$ & $\begin{array}{c}\text { Oven dry samples } \\
\text { pcs }\end{array}$ & $\begin{array}{c}\text { RH 45 samples } \\
\text { pcs }\end{array}$ \\
\hline 25 (Room temperature) & 4 & 4 \\
\hline 75 & 3 & 3 \\
\hline 100 & 3 & 3 \\
\hline 125 & 3 & 3 \\
\hline 150 & 3 & 3 \\
\hline 175 & 3 & 3 \\
\hline 200 & 3 & 3 \\
\hline 225 & 3 & 3 \\
\hline 250 & 3 & 3 \\
\hline
\end{tabular}

\section{Samples}

The samples were produced from spruce. Spruce was chosen, because it is a common species used in structural products, such as CLT and glulam. At the narrowest part, where the tensile failure is presumed to occur, their dimensions were approximately $20 \mathrm{~mm}$ x $7 \mathrm{~mm}$. The sample-specific variation was measured for each sample, and taken into account. The dimensions of the sample are illustrated in Figure 3.
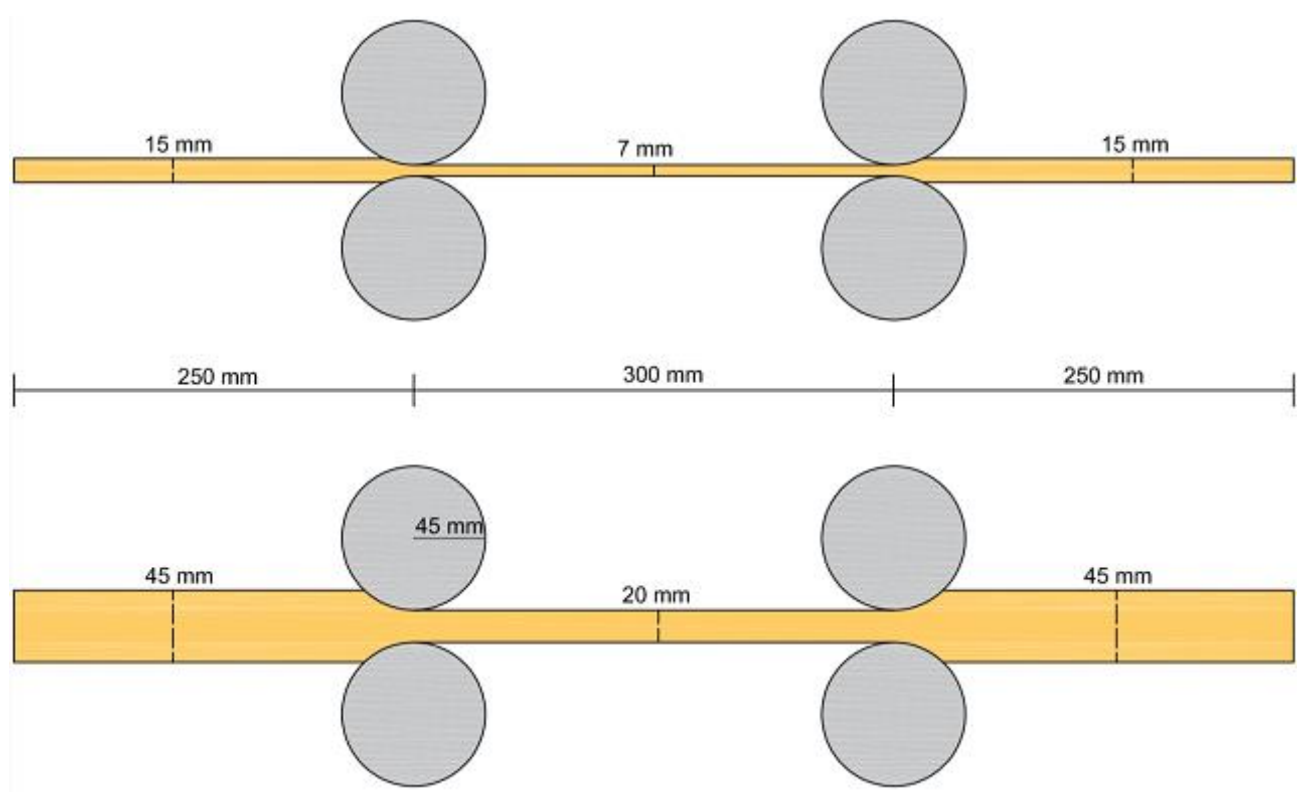

Figure 3. Dimensions of the spruce sample

In order to ensure the homogenic temperature profile throughout the sample, the sample had to stay in the oven for a fixed time before starting the actual experiment. This fixed time was determined via simulations and practical heating experiments.

\section{Experimental procedure}

Before the beginning of the actual tensile test experiment, the sample was put under a pre-load of $100 \mathrm{~N}$. This is done to firmly lock the sample into place, before the actual measurement of the strain starts. The tests were performed as position controlled, with a speed of $0,000051 / \mathrm{s}$, at which the upper clamp was set to move. The loading speed was chosen in order to cause the breakage of the sample at approximately 5 to 10 minutes into the tensile test. The tension was created into the sample by attaching it to two clamps, with the uppermost moving and the one on the bottom fixed into place. 
After the experiments in room temperature, the furnace was introduced into the setup. Based on the results of the heating experiments, the sample was placed within the furnace, which was then heated up $5{ }^{\circ} \mathrm{C} /$ minute to target temperature. After five minutes of reaching this temperature, the tensile test was started. The experimental setup is visualised in Figure 4.

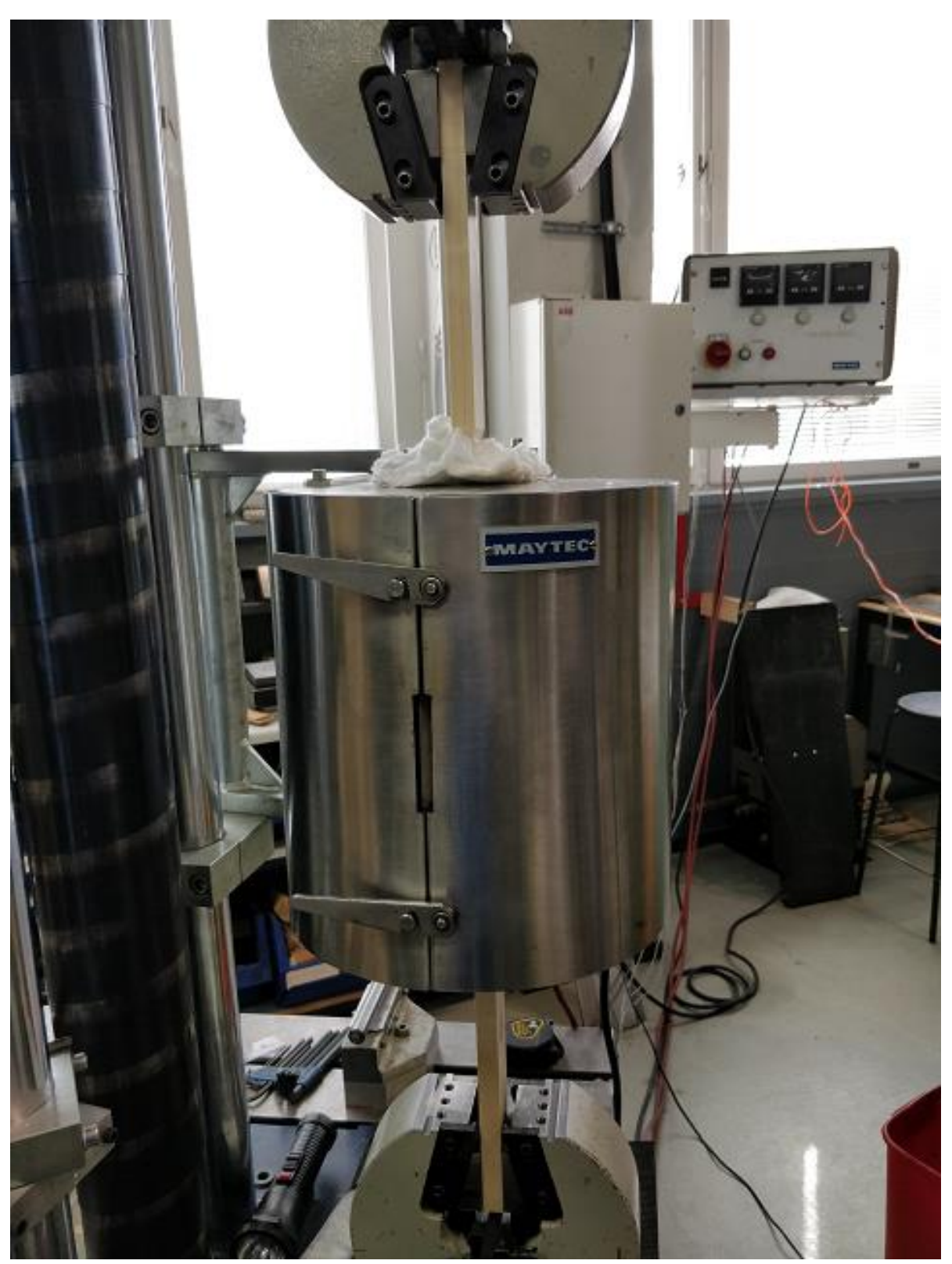

Figure 4. Experimental setup

Figure 5 illustrates the ending of an experiment at $225{ }^{\circ} \mathrm{C}$. The tensile strength experiments were all ended when the force applied to the sample dropped below $50 \%$ of its maximum value. This is why some of the samples, like the one in the figure, seem to be in one piece. In the picture we see both the strain measuring rods and the spots they were attached to, before they were retracted for their safety. The strain was measured in order to calculate the elastic modulus. We also see the insulation at the top and bottom of the furnace, used to keep the temperature within as steady as possible. The wooden sample itself has changed colour due to the exposure to high temperatures. 


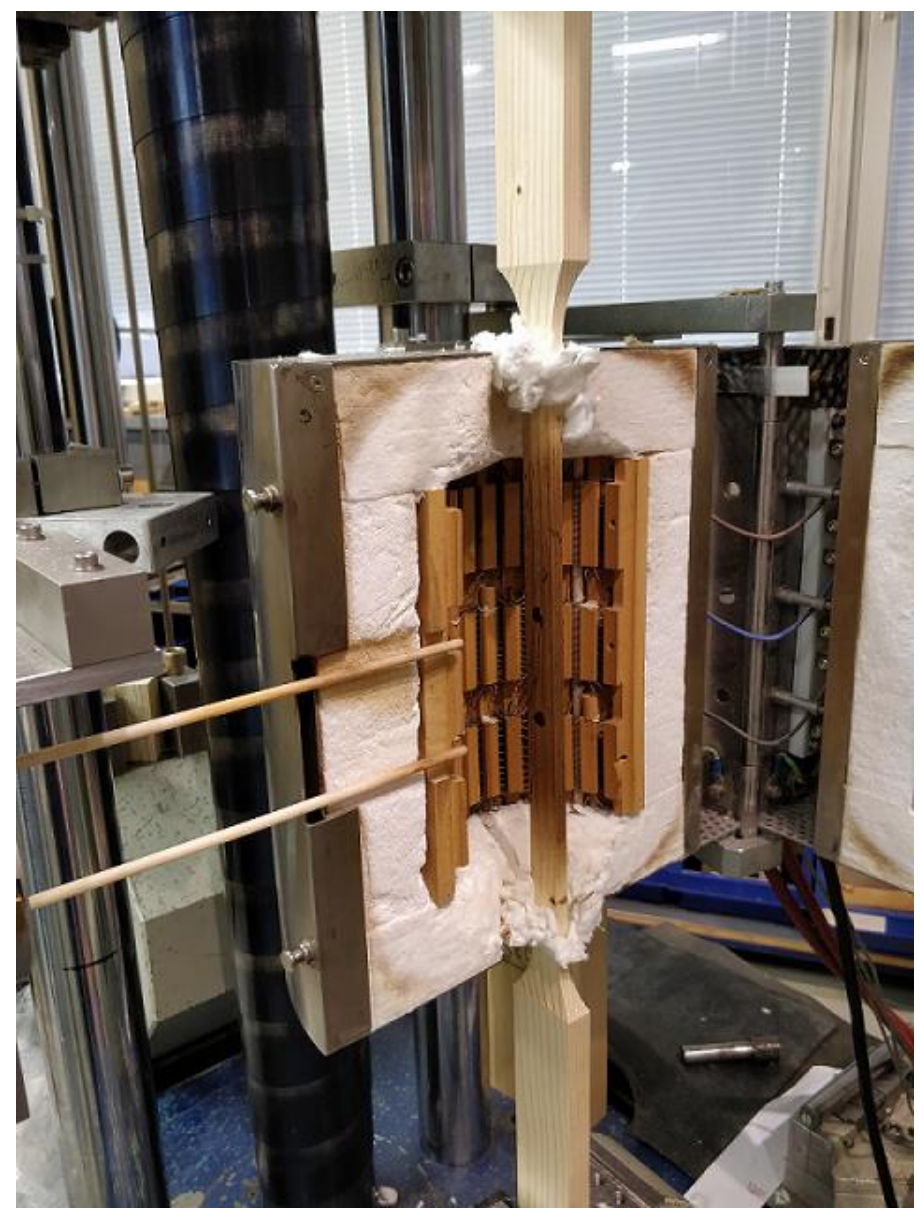

Figure 5. End of an experiment

\section{Result data}

Below we see the tensile strength and elastic modulus data tabulated for each set of testing conditions.

Table 2. Data gathered from the tensile strength tests

\begin{tabular}{|l|l|l|l|l|l|l|l|l|}
\hline $\begin{array}{l}\text { Temperature } \\
{ }^{\circ} \mathrm{C}\end{array}$ & $\begin{array}{l}\text { Initial } \\
\text { Humidity }\end{array}$ & \multicolumn{7}{l}{ Tensile strength } \\
$\mathrm{MPa}$
\end{tabular}




\section{Tensile strength results}

The results regarding the tensile strength are visualized in Figure 6. The ovendried samples are shown with an orange dot, and the moist samples with a blue dot. When comparing the placement of these data points, the effect of moisture content can not be specified. This is due to the fact that the variation of tensile strength between each sample is too big. With a larger number of specimen, the effect of the moisture content would most likely be observable.

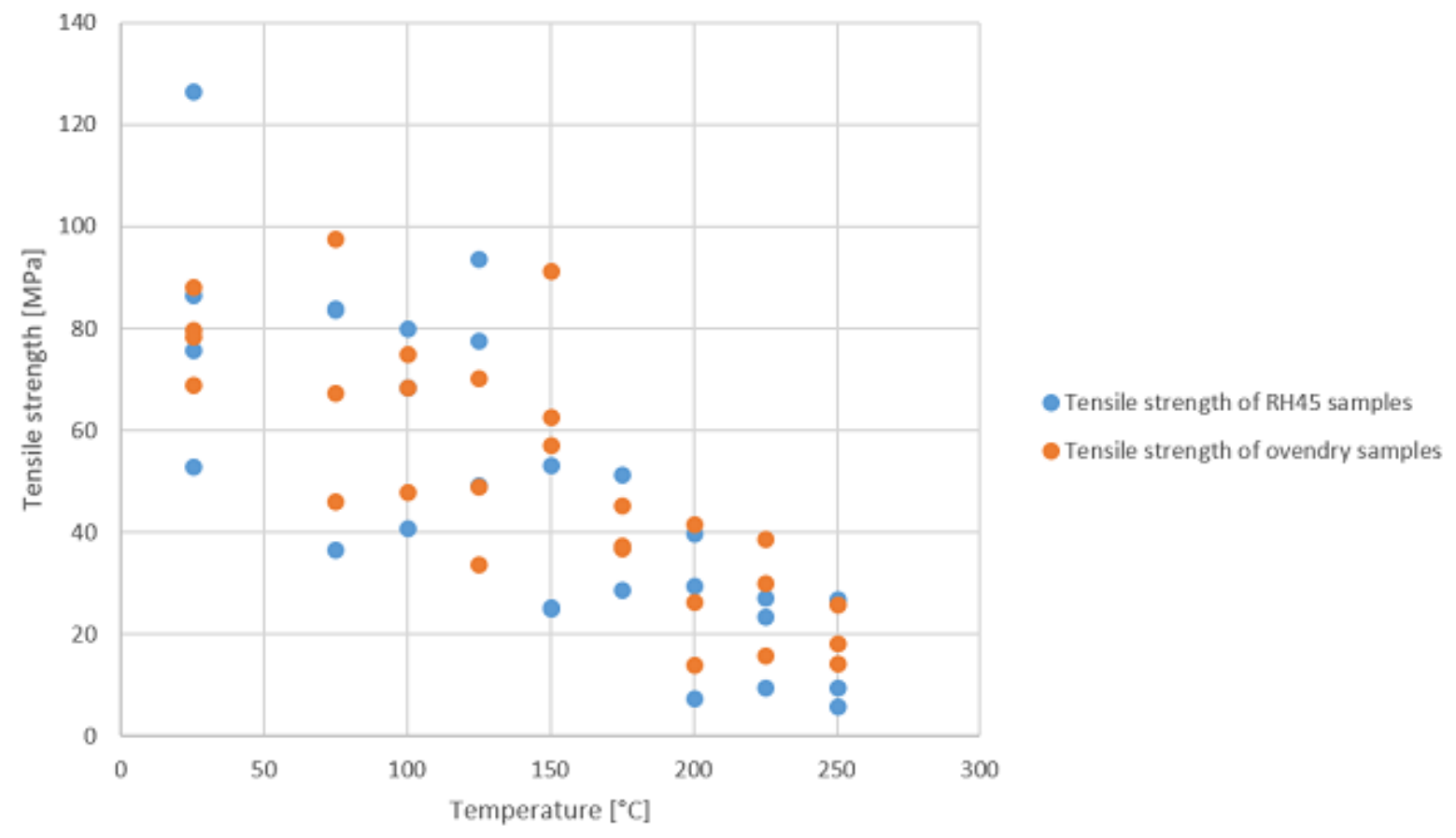

Figure 6. Illustration of the tensile strength data

As can be seen, there is a clear reduction in the tensile strength as temperature rises. When we take the average for the results for each test temperature, we can fit a line with the value of the coefficient of correlation, $\mathrm{R}^{2}, 0,9703$. This means, that the fitted line matches the dataset well (for a perfect match, the coefficient of correlation would be 1). Now, we can compare this fitted line with the reduction of tensile strength presented in Eurocode EN 1995-1-2. The reduction is given as percentage of maximum tensile strength, so a little fitting needs to be done. This is achieved by using the equation of the fitted line from experiments to find the value of "maximum strength" at $20^{\circ} \mathrm{C}$. This comparison is illustrated in Figure 7. 


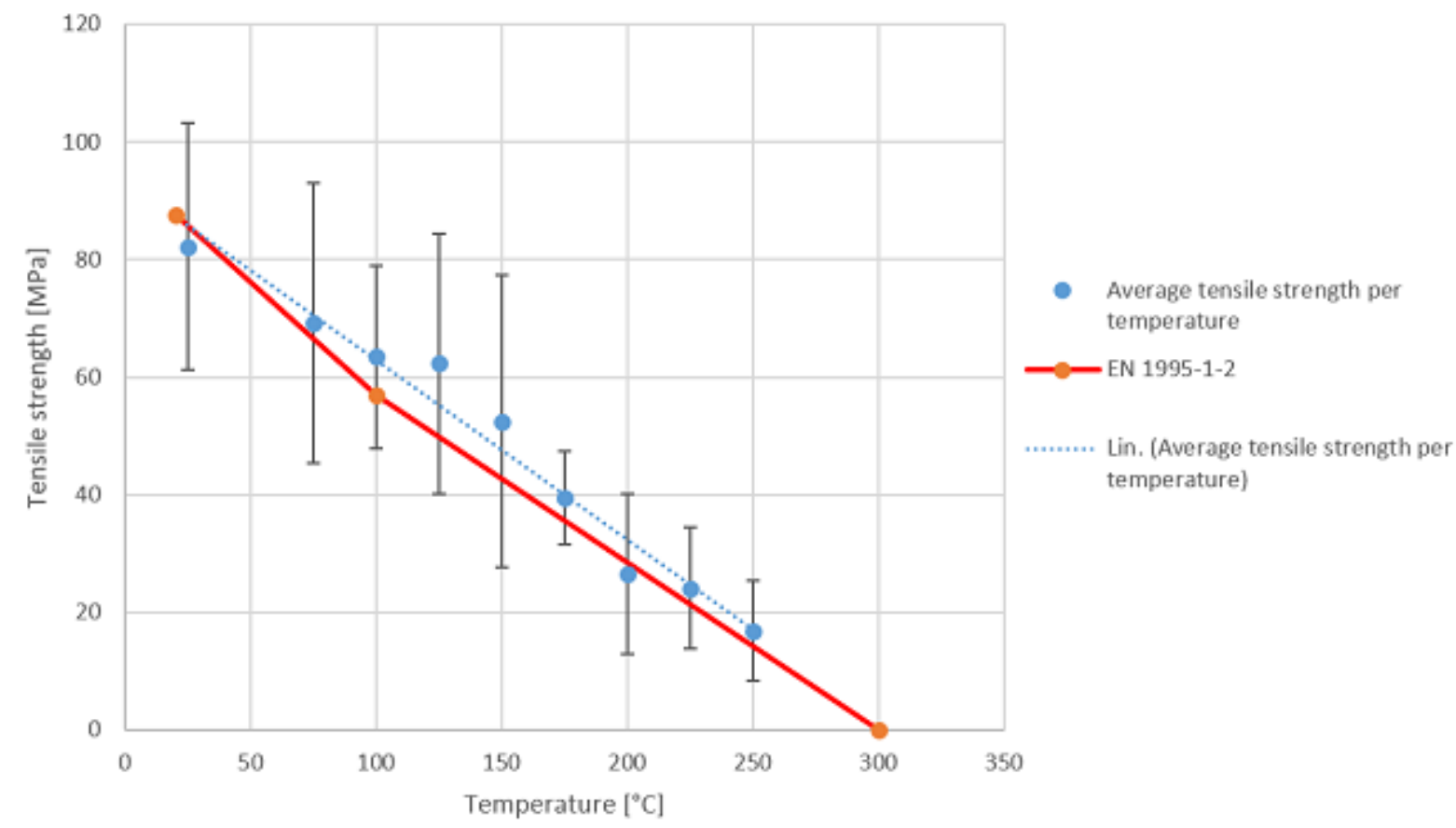

Figure 7. Comparison between the tensile strength data presented in the Eurocode and averaged experimental data

Even though there was a large variation in the data, the averaged values of tensile strength fit the values presented in the eurocode surprisingly well. However, trends such as the change in slope of the eurocode can not be found in the experimental data. By conducting a larger amount of tests, such trends might arise. Also, as the amount of samples increases, standard deviation may decrease. This is why the subject should be investigated further, with a considerably larger amount of specimen. Because the standard deviation of the averaged experimental results is on both sides of the plotted Eurocode data, it can't be stated that the Eurocode is on the safe side, which could be the first conclusion by only viewing the averaged data without its standard deviation.

\section{MAKING USE OF THE EXPERIMENTAL RESULTS}

As a vision to the future, a small software was also developed to link the temperaturedependent tensile strength to expected heating of structural timber in real-world fires, using fire simulations modelled with FDS (Fire Dynamics Simulator). The software creates a grid of temperature measuring points for the FDS code, and after the simulation is run, links each point's temperature with the corresponding relative strength. These relative strengths are then averaged for each time step. This way, an output of relative tensile strength through time is created, which can be used to analyse the fire-performance of the object of interest.

In order to demonstrate this, I created a small FDS model with a $2 \mathrm{~m}$ by $6 \mathrm{~m}$ by $2 \mathrm{~m}$ room. The room has a door in one end in order to provide the burning reaction with a sufficient amount of oxygen. On the other end of the room, there is a gasoline pool fire. The pool is modelled as a small square, with an area corresponding to a circular pool with radius of only $25 \mathrm{~cm}$, so it resembles a typical container. Above this fire there is a $4 \mathrm{~cm}$ by $4 \mathrm{~cm}$ wooden beam near the ceiling of the room. The relatively small dimensions of it were chosen in order to speed up the simulation process. This beam is modelled using the material properties of spruce, presented by Mikkola in one of his papers on the subject ${ }^{7}$. 


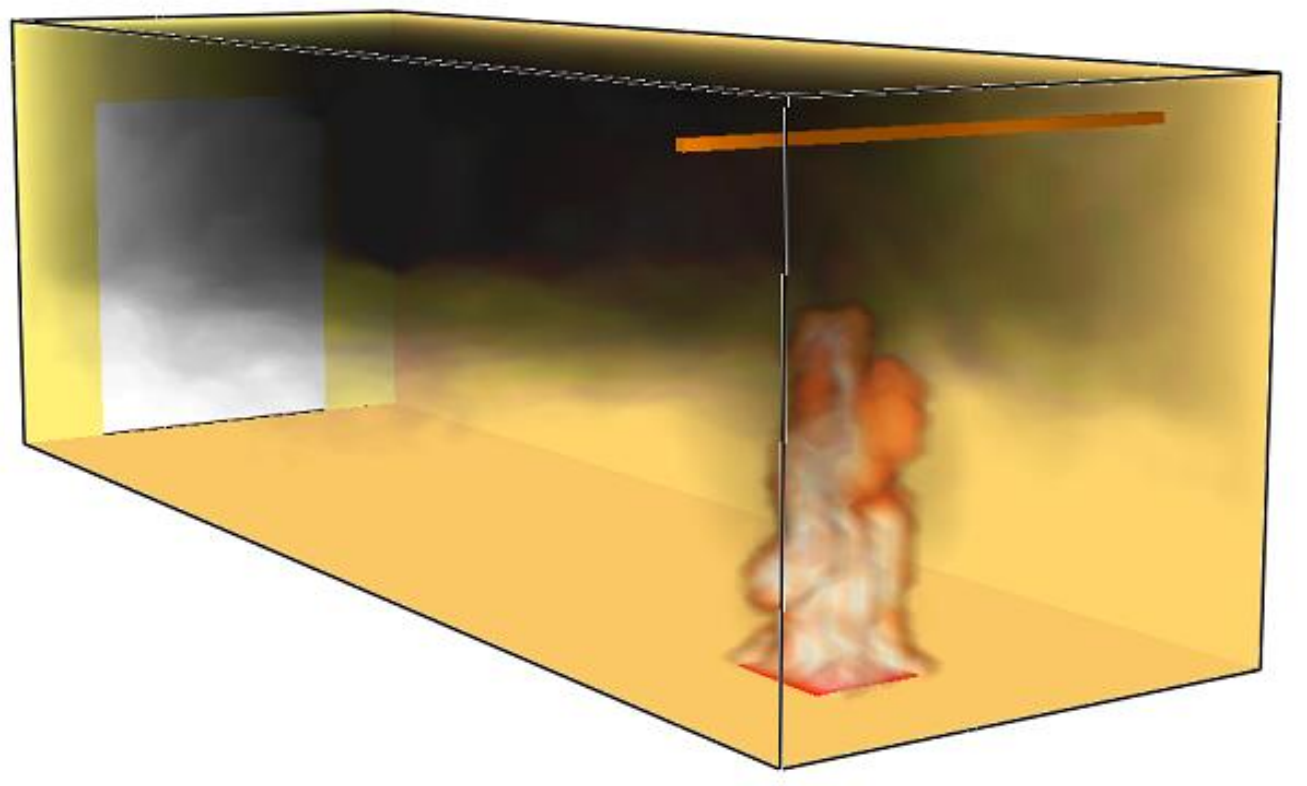

Figure 8. Geometry of the simulation model

The computational domain consists of two meshes; one outer mesh used to calculate the dynamics of the fire and space, and an inner mesh, used mainly to attach the necessary measuring points into the wooden beam. The grid spacing of the coarser main mesh is based upon the characteristic fire diameter, $\mathrm{D} *$, which is defined as ${ }^{8}$ :

$$
D^{*}=\left(\frac{\dot{Q}}{\rho_{\infty} C_{p} T_{\infty} \sqrt{g}}\right)^{2 / 5}
$$

where $\dot{Q}$ is the HRR, $\rho_{\infty}$ is the density of air, $c_{p}$ is the thermal capacity of air, $T_{\infty}$ is the ambient temperature and $\mathrm{g}$ is the nominal gravitational acceleration. In this case, the characteristic fire diameter $D^{*}$ is $0,6 \mathrm{~m}$

The ratio between the characteristic fire diameter, $D^{*}$ and the size of the grid cell $\partial x$ defines how many computational cells span over the characteristic diameter of fire. It should be noted, that the characteristic diameter of fire does not necessarily equal the physical diameter of fire. The bigger this ratio is, the finer the grid is, resulting in more accurate resolution of the calculation, but also in increased computational time. As a rule of thumb, a ratio of $D^{*} / \partial x$ between 5 and 10 provides fair results with reasonable computational time. However, the optimal ratio is very case-dependent, and should always be carefully considered. As an example, a validation study on the mesh resolution for NUREG-1824 provided adequate results in calculating the dynamics of the fire plume, at $D^{*} / \partial x$ ratios between 4 and $16 .{ }^{9}$ In this case, $4 \mathrm{~cm}$ was used for $\partial x$, resulting in

$$
\frac{D^{*}}{\partial x}=\frac{0,6 m}{0,04 m}=15
$$

which is deemed appropriate for the situation. The finer grid consists of one of these $4 \mathrm{~cm} \mathrm{x} 4 \mathrm{~cm} \mathrm{x} 4$ $\mathrm{cm}$ blocks being divided to a $1 \mathrm{~mm} \times 1 \mathrm{~mm} \times 1 \mathrm{~mm}$ grid. The finer grid is included to the model in order to be able to fix the measuring devices to the surface of the beam at $1 \mathrm{~mm}$ distances from another. Thus, eventhough using a fairly fine mesh as the main computational grid, having to divide only a small block into $1 \mathrm{~mm}^{3}$ pieces saves computational power. 


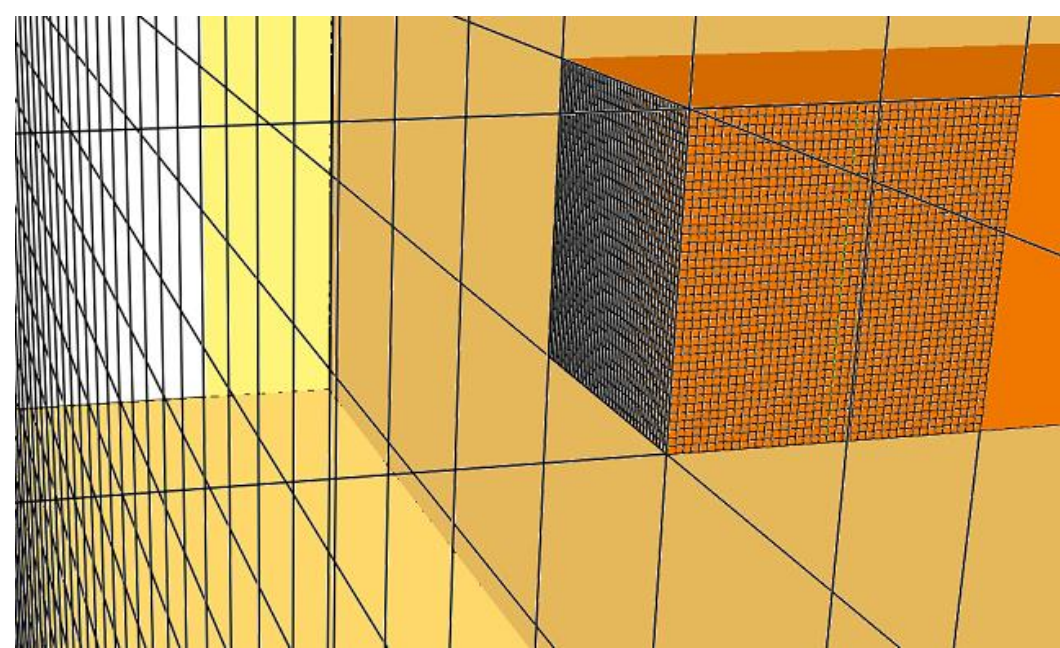

Figure 9. Clipped view of the alignments of the coarse mesh and the fine mesh within it

Once the FDS model is ready, the simulation is run. Then, the post-processing part of the small software created is used to analyse the results. Because the current version of FDS uses 1D heat conduction model, the utilization of the finer grid is not yet relevant. The parallel devices which will be created for the model, measuring the temperature at certain depths, produce exactly the same results because of the 1D heat conduction model within the obstacle. The surfaces of the obstacle all work independently, thus having no effect on one another. In future as 3D heat conduction will be included in FDS and the points within the obstacle are influenced by all surfaces, measuring techniques and fine 3D grids such as suggested in this paper might become useful. Eventhough the result data presented in this chapter comes only from a $1 \mathrm{D}$ heat conduction calculation, it can still be used in demonstrating the difference between using the values presented in the Eurocode and the data gathered from experiments presented in this paper as a reference for the analysis. Figure 10 shows the relative tensional strength derived based on both.

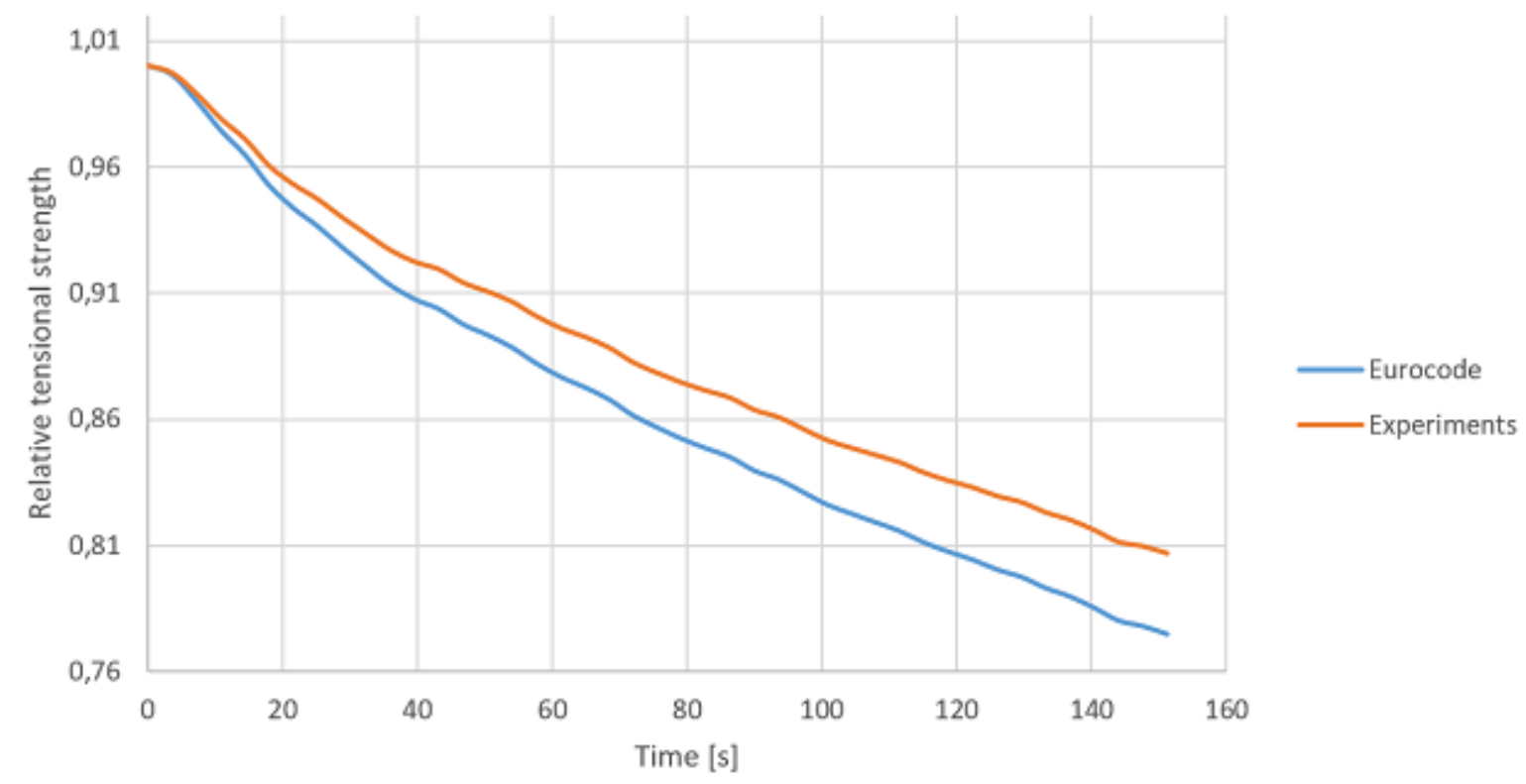

Figure 10. Results of the simulation based on the relationship between relative tensional strength and temperature

By comparing these two, it can be observed that the interpretation based on the Eurocode is on the safer side, as it states that a certain decreased value of the relative tensional strength is reached earlier than in the interpretation based on the experiments I conducted. Also, as time progresses the 
differentiation between the two curves presented grows larger. This indicates that the wooden beam starts to heat up from the inside too, as the biggest separation between the experimental data and the Eurocode was found near $100{ }^{\circ} \mathrm{C}$. The simulation was only run for 152 seconds due to its massive CPU usage and slow advancement. However, it is already adequate for demonstrative purposes within this paper.

\section{Limitations}

The current version of FDS uses 1D heat conduction. This means, that by the utilization of the finer grid and the multiple parallel measuring points, no additional value is gained. However, as the 3D heat conduction models advance and become common practice, this approach could become widely used. By combining the individual point data of the temperature, to a model which contains the direction and magnitude of the stress at the same point would provide very useful data on structural analysis during fires. Before this can be done, it has to be properly tested, adjusted and evaluated.

The model and its post-processing presented within this paper thus work only as a prototype that can be exploited in the future. Because the heat conduction in the model is only calculated in 1D, it can not be used to determine the realistic temperature profile within the object. The measuring points created are now all in one plane, which has to be predetermined. In the future, the temperature profile could be acquired for the whole beam. This would mean, that the section under observation could be chosen after the simulation is run. Also, a graphical representation of the temperature profile could be created. With this, the user could see the advancement of the charring front, as well as the heat profile within the object at desired times.

The material model within FDS is an approximation at best, and especially for wood, the simulation and real-life behaviour and properties may vary. This should be taken into account when using this type of analysis, and the results should not be applied to design purposes without thorough consideration and critical thinking.

\section{CONCLUSIONS}

The strength properties of wood in high temperature have been studied to some extent, but more focus should be directed to the subject. As the data gathered by different researchers varies quite a bit, it is difficult to know which data describes the effect of temperature on the tensile strength of wood most accurately, and is the best for real-world applications. In order to produce scientifically accurate and significant data, the methods used in collecting and evaluating it have to be adequate, and uncertainty has to be addressed accordingly.

Eventhough the data gathered on the tensile strength of the samples shows clear correlation with the data presented in the eurocode, the amount of samples used in the tensile tests presented in this paper is too little to make reliable and accurate statements. As a further improvement to the experiment setting, strain data could be collected on both sides of the samples, which was now not possible due to the restricting geometry of the furnace used. Also, conducting studies to demonstrate whether or not the time the sample stays in elevated temperature has any effect on its elastic and strength properties should be conducted, while measuring the strain caused by shrinking due to loss of moisture and thermal expansion. Overall, the experiments conducted within this paper correlate well with the relationship between tensile strength and temperature presented in the Eurocode EN 1995-1-2. This is a good thing, indicating that using the methods presented within the Eurocode are in line with reality and will not cause dangerous design decisions, provided that they are used correctly.

Eventhough the post processing of the simulation model presented in this paper is mainly a vision of the future as it would require 3D heat conduction model, the results of the tensile strength experiment can be utilized also with current simulation technology. This could be done e.g. by keeping tabs on the temperature development of each side of the object, and by using the known heat conduction properties within wood, calculating the temperature profile by hand. However this would still be only 
an approximation, and very time consuming. The simulation of fires is gaining more and more ground among the fire safety engineering community as the tool for proving buildings-to-be safe, so further research should be directed towards material properties under exposure to elevated temperatures. For wood, this could be done by continuing along the same testing principles presented and evaluated in this paper. By making use of the data gathered, more effective tools for engineering could be developed, leading the whole building industry to a brighter future.

\section{REFERENCES}

${ }^{1}$ CEN. Eurocode 5: Design of timber structures - part 1-2: General structural fire design, 2004.

${ }^{2}$ Liu, W.-T., Tsai, M.-T., and Fitriana, L. Experimental study on residual compressive strength of bamboo column under fire with different time limitation. World Conference on Timber Engineering 2016, 5235-5242.

${ }^{3}$ Ranta-Maunus, A. The Viscoelasticity of Wood at Varying Moisture Content. Wood Science and Technology, Vol. 9 (1975), 189-205.

${ }^{4}$ König, J. Timber frame assemblies exposed to standard and parametric fires. 2000.

${ }^{5}$ B.A.-L. Östman. Wood tensile strength at temperatures and moisture contents simulating fire conditions. 1985.

6 Schmid, J., et all. The Reduced Cross-Section Method for Evaluation of the Fire Resistance of Timber Members: Discussion and Determination of the Zero-Strength Layer. Fire Technology, 51 (2015), 1285-1309.

${ }^{7}$ Mikkola, E. Puupinnan syttyminen. VTT Tiedotteita 1057. 1989.

8 McGrattan, K., Hostikka, S., McDermott, R., Floyd, J., Vanella, M., Weinschenk, C., Overholt, K. Fire dynamics simulator user's guide, 2017.

${ }^{9}$ U.S. Nuclear Regulatory Commission. Verification and validation of selected fire models for nuclear power plant applications. volume 7: Fire dynamics simulator (fds), 2010. 